\title{
Condiciones para el buen Resultado de la Psicoprofilaxis Aplicada al Parto
}

\author{
Dr. Hernando Amaya-León \\ Del equipo "EMESFAO” - Bogotá
}

En la teoría y práctica de la preparación sicoprofiláctica hay varios componentes básicos que deben ser analizados por separado, pues de su apreciación exacta y armónica resultará el éxito o fracaso del sistema en la práctica. Estos son:

$1^{\text {O }}$ - La mujer embarazada.

$2^{\circ}$ - El médico.

$3^{\circ}$ - La instructora.

$4^{\circ}$ - Las condiciones ambientales que nos rodean.

La EMBARAZADA, constituye sin duda el factor más importante. La educación debe hacerle comprender y valorar con toda realidad que desde el nacimiento, todo su organismo ha sido creado y conformado para la maternidad y que ese momento sublime no puede ser ignorado por ella; de ahí que se procure llevarle todos los detalles de conocimiento sobre la fecundación, cambios durante el embarazo, evolución del parto, etc. Del embarazo como fenómeno natural y lógico y no como "enfermedad que dura nueve meses" (De Lee), nacerá un estado de confianza y satisfacción que repercutirá en un parto tranquilo y consciente y probablemente sin dolor.

Es por esto que la primera condición para obtener buenos resultados con el médico, es insistir y obtener de las señoras, una asistencia puntual a las conferencias y prácticas que se les dictan. De allí surgirá el natural interés y entusiasmo por el método; el convencimiento sincero de la nobleza del mismo se irá adquiriendo a medida que se avance inteligentemente por los escondrijos antes ignorados de la maternidad; porque es casi imposible de comprender, como mujeres madres de 5 o más hijos no tienen la menor idea de cómo es el aparato genital femenino, cómo 
se produce la fecundacióin. cuáles son los períodos del alumbramiento y en esas condiciones, cada parto es la culminación de una serie de fenómenos misteriosos, que han ido incorporándose a la mente femenina como procesos más o menos tenebrosos, peligrosos, y por tanto como fuentes de sufrimiento y de dolor. Tales son los orígenes de los reflejos que han ido condicionándose en su sistema nervioso desde miles de años atrás, y tales son los que una buena educación psicoprofiláctica debe transformar en otros favorables para el parto sin dolo?

En el método que nos preocupa han surgido dos escuelas o tendencias, que son defendidas acremente por sus partidarios: la rusa, pawloviana, basada en los fenómenos netamente fisiológicos de la actividad nerviosa superior y los llamados reflejos condicionados; y la anglo-sajcna, con Read a la cabeza, en donde la concepción básica es el fenómeno psicodinámico. Unos y otros se discuten, y en ocasiones se atacan sin cuartel: podría decirse que hay quienes piensan en materialismo y espiritualismo como doctrinas filosóficas que han ido incorporándose a cada una de tales teorías.

A nuestro entender, el método psicofísico ideal debe tomar de las dos tendencias y fundirlas en una sola; ambas son ciertamente razonables, $\mathrm{y}$ en cierto punto, complementarias; nunca pensamos que se contrapongan. El mal entendimiento que ha surgido, es posible que sea más un problema de política internacional que un verdadero distanciamiento científico.

Sabemos muy bien que una mujer en trance de parto, con un apoyo verbal eficiente y modificaciones respiratorias adecuadas, obtiene un parto indcloro en muchas ocasiones, a pesar de no haber logrado entrenamiento previo satisfactorio; y los llamados casos de "preparación extemporánea" son el mejor argumento de tales teorías puramente organicistas, reflexológicas. Pero pensamos: éstos son éxitos locales, personales, que favorecen a esa mujer en sí, pero muy poco a la comunidad, considerada ésta como elemento dinámico; es un éxito, sí, pero no racionalizado; y así podrán lograrse mil, un millón, pero se seguirá actuando en la zona no conciente de la personalidad temenina, y por tanto la labor de psicoprofilaxis tendrá que ser mucho más larga, aunque aparentemente sea un éxito inmediato la estadística de casos magníficos logrados. 
Pero si a esas prácticas de resultados indudablemente sobresalientes agregamos una detallada instrucción prenatal tendiente a reeducar el psiquismo deformado de la mujer en sus conceptos relacionados a la maternidad, y favorecemos el estado físico por medio de ejercicios que preparan a la futura madre como se adiestra un deportista, crearemos una nuevo ambiente comunal que por lógica será más beneficioso.

Kroger y Freed afirman que el embarazo debe considerarse como la culminación del desarrollo psico-sexual femenino; y que la existencia o la falta de un desarrollo emocional sano durante el período de formación, una educación sexual apropiada, una adolescencia inadecuada, una satisfactoria adaptación al matrimonio y un auténtico deseo de maternidad indican la capacidad psicológica de la mujer para la maternidad.

$\mathrm{Y}$ todas estas condiciones anotadas por tales autores deben encontrarse reforzadas en el método psicoprofiláctico para el parto. No hay duda, que cuando más equilibrada se encuentre una mujer frente a esos postulados, mayores serán las probabilidades de éxito del método. Cuando la psicoprofilaxis sea un método generalizado y la educación psicosexual del hombre y la mujer abocada desde la niñez, se habrá logrado el mejor aporte a la estabilidad emocional del género humano, y las guerras, la violencia, el odio y el dolor dejarán de ser patrimonio de nuestras generaciones.

Mucho se ha discutido sobre el tipo nervioso más favorable para obtener éxito con el método, sin llegar a ningún resultado práctico porque tal clasificación tropieza en la práctica con muchas dificultades, como lo han confesado los mismos autores rusos. Actualmente selecionamos nuestros pacientes teniendo en cuenta la capacidad de adaptación del sistema nervioso a las condiciones ambientales y la posibilidad de orientar en forma favorable la actividad nerviosa superior por medio de la enseñanza.

Por otra parte desde el punto de vista obstétrico tampoco se debe hacer ninguna discriminación con miras al éxito del método; si bien es cierto que los mejores resultados se obtienen en casos eutócicos, también lo es el que una paciente distócica con preparación sicoprofiláctica se encontrará en mejores condiciones frente a una intervención. en caso de ser ésta necesaria. Como lo ha puntualizado P. Vellay la sicoprofilaqis beneficia a toda mujer sin que interese la paridad, la edad, la raza, el estado civil, ni 
la presencia de distocias o complicaciones concomitantes en el embarazo.

El MEDICO, como un verdadero director de escena, adquiere una importancia vital para el buen resultado del método. Sus conocimientos científicos tienen que ser los de todo buen obstetra, capaz de valorar y resolver cualquier situación anómala que se presente durante el embarazo, el parto o el puerperio. Pero en la práctica del método psicoprofiláctico, el médico debe reunir otras condiciones, ciertamente indispensables: deja de ser el profesional que se presenta en el último período del parto para convertirse en un colaborador permanente, en un verdadero amigo de la señora embarazada, a la cual está no solamente prestando atención técnica sino aconsejándola, en una palabra, educándola.

$Y$ téngase muy en cuenta que se trata no únicamente de una educación aislada, personal, sino que tiene como objetivo primordial el llegar por su intermedio a todas las mujeres de la comunidad; porque se trata en fin de cuentas de una labor profiláctica humana, tratando así de relevarlas de esos factores que las han acompañado y condicionado por muchos años, y que han convertido al parto en momento angustioso y de dolor.

El médico, como educador, debe poseer los méritos para cumplir su objetivo a cabalidad; como primero, estar convencido de la bondad de lo que enseña, porque muchos fracasos tienen en el fondo esa razón: la palabra que se transmite puede llevar el raciocinio lógico de la materia, pero algo traiciona a quien lo dice, y llevando así el germen de la desconfianza en el subconciente del oyente; y la semilla del fracaso se ha sembrado.

Luego, el médico debe ser realmente humano; esta frase debería ser paradojal, pero desgraciadamente no lo es en muchos casos; y no se crea que es una agresión al buen nombre de nuestro cuerpo profesional; es una falla universal, en todos los campos y actividades del saber.

Aquellos a quienes la Providencia nos ha colocado en una situación ligeramente superior al resto de nuestros congéneres, nos hace creer que somos superdotados; y nos olvidamos que el número de éstos es realmente ínfimo. $\mathrm{Y}$ esa posición artificial nos aleja casi siempre de nuestros deberes para con el conjunto humano al que pertenecemos. Y así, el escritor dice cosas que no entiende ni él mismo; el artista pinta para que lo interprete una 
minoría; el músico no transmite sino el desconcierto y la incertidumbre; el legislador no intuye las mayorías; el internacionalista no es sino un mal nacionalista; el clérico olvida que Dios es para todos; y así sucesivamente. $\mathrm{Y}$ todos nos hemos deshumanizado poco a poco; y éste es el germen de la violencia, la lucha de clases y razas, de las guerras, del dolor.

Debemos humanizarnos; y el médico frente a la embarazada, tiene el deber de situarse en el plano mental de su paciente: estudiar sus conflictos, tratar de resolverlos, ajustar su vida psicosexual a la realidad; en una palabra, fomentar su estabilidad emocional y física. Llegando a ella de esa manera, estará haciendo una verdadera labor de psicoprofilaxis.

La poderosa influencia del obstetra sobre su paciente es interpretada por algunos como un fenómeno de transferencia. Quijada dice que "los que siguen el método sicoprofiláctico actúan en lo inconciente y reprimido de las gestantes, con una acción de tipo hipnótico, aunque creyeran los rusos haberla descartado con la implantación de clases o cursillos". Agrega además que "la gestante, inconscientemente encuentra en el médico a un ser protector, amoroso que comienza a darle seguridad. La autoridad, la bondad, el interés que ella sentía en su padre se reproducen en el médico. Es más, como su padre que todo lo sabía y se lo explicaba, la persona del especialista toma caracteres de omnipotencia.

El médico que se dedique a la práctica del método sicoprofiláctico debe imponerse una modificación total de su mentalidad y criterio frente a la embarazada con miras a lograr una humanización de la obstetricia. De su vocabulario debe suprimir el término "dolor" y decir más bien "contracciones uterinas" o "contracciones del parto". Hay quien sostiene que el día que se logre suprimir la palabra "dolores" en el parto los resultados del método serán superiorísimos a los obtenidos en el presente.

Es importante anotar la manera como se pone en práctica la preparación sicoprofiláctica. Para que ésta dé sus mejores resultados y para que sus beneficios se extiendan a toda la comunidad y al mismo tiempo para que no implique excesivo recargo de trabajo para el obstetra, es conveniente llevarla a la práctica por el sistema de trabajo en equipo. Con trabajo individual y aislado es posible también obtener la preparación de las pacientes pero a costa de un mayor esfuerzo por parte del médico, con resultados 
inferiores y con poca o ninguna repercusión educativa en el medio social en que se actúa.

El equipo puede ser pequeño y constar del mínimo requerido de personas: el obstetra y la enfermera instructora. El trabajo será mucho más fácil y los resultados mejores a medida que aumenta el número de miembros del equipo: tres a seis obstetras que a más de dictar la parte teórica del curso atiendan el parto de las pacientes; y dos y cuatro enfermeras instructoras encargadas no solo de las clases prácticas sino también de apoyar a las pacientes durante el trabajo.

El número de miembros del equipo depende del medio en que se trabaje y el número de pacientes que se atiendan. En todo caso para que el trabajo sea efectivo, el equipo debe tener organización, método, programas definidos, unidad de criterio, sentido humanitario de la obstetricia y apostolado en el desempeño de sus funciones.

De ser posible, el equipo debe valerse de los servicios de un pediatra para que desarrolle el tema de puericultura y ponga de presente las ventajas del método en el niño. Igualmente se puede solicitar los servicios de un sicólogo cuyas funciones consistirán en estudiar, tratar y explicar todos los problemas emocionales de las embarazadas.

La enfermera instructora o preparadora es un elemento fundamental e indispensable para el buen resultado del método. Las condiciones principales que debe reunir consisten en un buen conocimiento y práctica de enfermería referente a la maternidad (en cuanto sea posible, la enfermera debe ser graduada) educación y trato amable con las pacientes, además de suficientes conocimientos y convencimiento del método. Si la enfermera es casada y si en sus partos ha seguido la instrucción sicoprofiláctica, su labor educativa y su influencia sobre las pacientes serán más decisivas. Buen número de fracasos en nuestro medio, como en toda parte donde se inicia el método, es debido a fallas en la enfermera instructora ya sea por ausencia durante el parto o por deficiente preparación para adelantar los cursos.

La importancia de la instructora es interpretada por Quijada en "un enfoque sicoanalítico del parto sin dolor" de la siguiente forma: "Hay otro personaje que desempeña un importante papel en el mismo juego de las fuerzas síquicas: la comadrona. Esta 
figura va a tocar en lo inconciente y lo reprimido todo lo relativo a los intercambios afectivos con la madre. Así pues esta figura femenina acogedora, complaciente y educadora va a despertar vivencias amorosas. Es como si mentalmente se dijera: esta persona que me inspira respeto y amor, tiene mucho de mi madre; si ella me ayuda es porque soy capaz, sin peligro alguno, como me dice, de llevar mi objetivo hasta el fin".

Por último, las CONDICIONES AMBIENTALES que nos rodean. Causal de gran número de fracasos del método en la práctica, y valla a la psicoprofilaxis en general. La realidad es que todo, o casi, está en su contra.

La mujer ha nacido en medio de dolores, y las conversaciones, referencias, citas al respeto y recuerdos de todo género, hacen que la niña viva el dolor del parto como cosa lógica y natural. Todo nacimiento de que se hace mención, lleva en sí un rasgo de heroismo y sufrimiento que crea en esa mente un ambiente de temor. Ya en la vida prematrimonial, sus lecturas, novelas radiales, representaciones cinematográficas y de televisión etc., hacen que tales ideas se confirmen a cada momento. $Y$ no hay educación psicosexual adecuada que podría desvirtuar tales conceptos erróneos.

Una buena instrucción prenatal lleva como objetivo llenar esa falla educativa en la mujer; y aún más; tiende a convertirse en un factor psicoprofiláctico comunal de gran valor, puesto que aspiramos a que las hijas nacidas de madres conocedoras del método y que lo hayan practicado, ya sean educadas de modo diferente, y a su vez transmitan a sus hijas la misma línea de conducta y entonces, la bondad del método será mucho más evidente, y sus resultados cada vez más perfectos.

Es por esto, que quienes practicamos el método, deseamos y buscamos su propagación de todos los ámbitos médicos y educacionales y a través de conferencias, simposios, películas, libros, etc., llevamos nuestros ideales por doquier; y todo grupo que se forme, toda mujer que sea una convencida del método, será el mejor medio de propaganda; algún día, cuando la mayoría del género humano haya logrado vencer los temores adquiridos a través de tantos años, descondicionarán sus reflejos dolorosos del parto, y esta condición dejará de ser el castigo que nos impuso la ignorancia y el terror. 
En cuanto a la práctica rutinaria del método, se encuentran serios inconvenientes, nacidos ellos de los errados conceptos que hasta ahora han prevalecido. Clínicas no adaptadas para el método, en donde se atienden señoras con preparación o sin ella, y en donde los gritos y gemidos desafortunados pueden descondicionar una mujer bien instruída. Personal secundario, internos, enfermeras, religiosas, que ignorantes del sistema, son un factor negativo constante: no podemos negar ni olvidar, que un gesto inadecuado, una pregunta mal intencionada pueden significar el fracaso de una señora que pasa por la prueba del método psicoprofiláctico.

El logro de personal adecuadamente entrenado, clínicas y hospitales adaptados juiciosamente, en suma modificaciones ambientales que hagan del parto un momento tranquilo y amable, serán motivos de éxito del método y contribuirá a la difusión lógica y segura de la sicoprofilaxis para el parto no doloroso.

El éxito del método se debe también a la adaptación especial de las clínicas de maternidad y a la educación de todo el personal que en ellos trabaja además de que se cuenta con un mayor número de médicos y enfermeras. Esto supone naturalmente una mayor erogación económica que en todo caso es justificable en vista de la mayor seguridad física y emocional que el método proporciona a la mujer Rossernvasser anota que "el gran número de éxitos en la Unión Soviética se explica porque allí el presupuesto para la salud pública es abultado y se cuenta con un personal de médicos y enfermeras muy numeroso; por ejemplo en una maternidad de Moscú (Clara Zetkin) en 150 camas, hay 247 personas especializadas, de las cuales 32 son médicos. En el Instituto de Ginecología y Obstetricia de Leningrado, que dirige el Profesor Nicolaiev, hay un servicio de maternidad con 300 camas, con un personal especializado de 600 personas, de las cuales 100 son médicos. También en maternidades pequeñas se observa esta misma preparación; en una de estas clínicas de provincia con 10 camas trabajan tres obstetras, tres parteras y cuatro enfermeros. "Si a todo esto agregamos la participación de neurólogos, fisiólogos, clínicos, etc., en estos servicios, se pueden imaginar los recursos con que cuentan. Además en Rusia, la propaganda en fábricas, en diarios, revistas, radio y televisión es intensa y permanente con lo cual se prepara o condiciona la mente del pueblo para el parto sin dolor". 
El resumen de las líneas anteriores se reduce a una sola palabra: Educación; de la mujer, del médico, del personal que nos rodea; a la readaptación de los sistemas y organizaciones; en fin, a obtener la racionalización y comprensión del parto como fenómeno natural.

La verdadera psicoprofilaxis vendrá cuando todas estas condiciones se aúnen y sean elementos acordes con las ideas que primen en la conciencia humana.

\section{BIBLIOGRAFIA}

GOODRICHE F. W. and THOMAS, H.: Clinical Study of Natural Chilbirth: Preliminar Report from Teching Ward Service, Am. J. Obst. \& Gynec. 56: 175 (Nov.) 1948.

READ G. D. : Chilbirth Without Fear. The principles and Practice of Natural Childbirth. New York Harper \& Brothers, 1944.

VOLLMER, A. M.: Clinical Experiences and observations on the use of Relaxation Methods in Obstetrical Practice. Problems of early infancy Tr. Second Conference, Marchal 2 1948. New York, Josiah Jr.; Foundation.

KROGER y FREED Ginecología sicosomática. Salvat. Barcelona 1955.

VELLAY P. Conferencia de sicoprofilaxis. Clínica Restrepo. Bogotá D. E. 1959.

VELLAY P. Comunicación al Congreso de Turín. 1957.

AMAYA-LEON, H. Conferencia "Condiciones favorables al Método S. P. Curso de Post-graduados. Cali. 1958.

SILVA MOJICA C. R. "Condiciones para el buen resultado del método S. P." Curso de post-graduados. Cali 1958.

QUIJADA HERNAN Consideraciones sicoanalíticas sobre partos distócicos. Edit. Paz Montalvo. Madrid 1957.

URAN G. Y MAZZ RAIMONDI y col. "Preparación sicoprofiláctica para el parto". Boletín de la Sociedad de Obst. y Gin. Bnos. Aires. Mayo 1956.

SCHAWARTZ R. Resultados de nuestra experiencia con el método S. P. Boletín Sociedad Obs. y Gin. Buenos Aires. Junio 1956. 